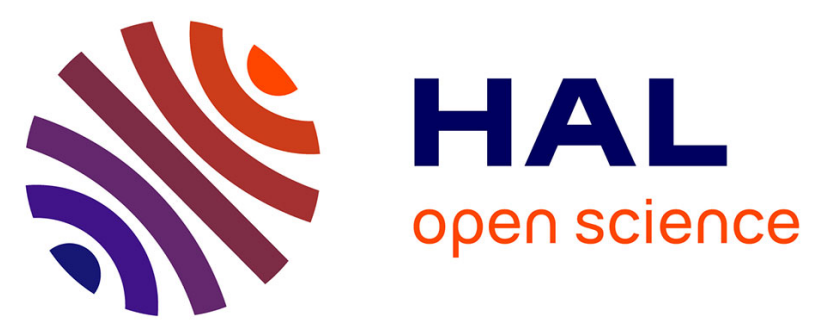

\title{
A Tool to Estimate Land-Surface Emissivities at Microwave frequencies (TELSEM) for use in numerical weather prediction
}

Filipe Aires, Catherine Prigent, Frédéric Bernardo, Carlos Jiménez, Roger Saunders, Pascal Brunel

\section{To cite this version:}

Filipe Aires, Catherine Prigent, Frédéric Bernardo, Carlos Jiménez, Roger Saunders, et al.. A Tool to Estimate Land-Surface Emissivities at Microwave frequencies (TELSEM) for use in numerical weather prediction. Quarterly Journal of the Royal Meteorological Society, 2011, 137 (656), pp.690-699. 10.1002/qj.803 . hal-01117326

\section{HAL Id: hal-01117326 \\ https://hal.science/hal-01117326}

Submitted on 16 Feb 2015

HAL is a multi-disciplinary open access archive for the deposit and dissemination of scientific research documents, whether they are published or not. The documents may come from teaching and research institutions in France or abroad, or from public or private research centers.
L'archive ouverte pluridisciplinaire HAL, est destinée au dépôt et à la diffusion de documents scientifiques de niveau recherche, publiés ou non, émanant des établissements d'enseignement et de recherche français ou étrangers, des laboratoires publics ou privés. 


\section{RMetS}

Royal Meteorological Society

\section{A Tool to Estimate Land-Surface Emissivities at Microwave frequencies (TELSEM) for use in numerical weather prediction}

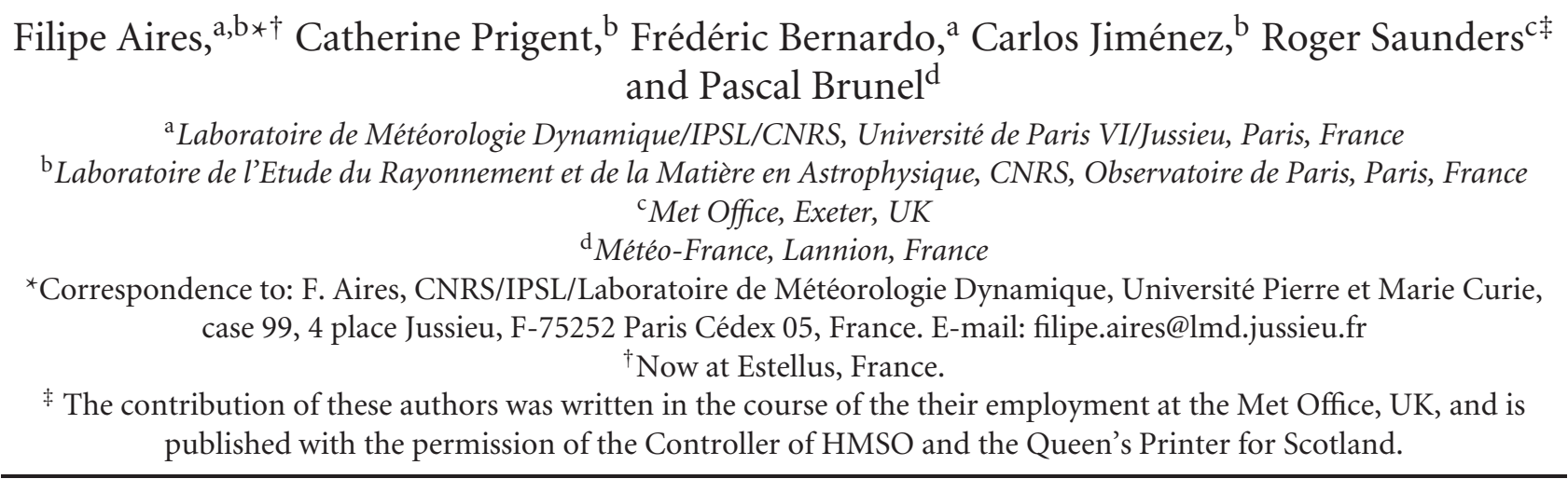

A Tool to Estimate Land Surface Emissivities at Microwave frequencies (TELSEM) has been developed for use with the Radiative Transfer for the Television and infrared Observation satellite operational Vertical Sounder (RTTOV) model. Its objective is to provide a good estimate of the microwave surface emissivity to improve the retrieval of atmospheric profiles or the direct assimilation of radiances in numerical weather prediction (NWP) models using microwave sounder data over land. TELSEM provides emissivity estimates and error-covariance matrices for all land surfaces between 19 and $100 \mathrm{GHz}$ and for all angles and linear polarizations. It is based on a pre-calculated monthly-mean emissivity climatology derived from Special Sensor Microwave/Imager (SSM/I) observations. Results show that when TELSEM is used, radiative-transfer simulations are closer to real observations. This is important when RTTOV is used to generate simulated datasets, to analyze new instrument concepts or for assimilation schemes. Experiments also show that TELSEM can be applied to provide a first guess for the surface emissivity down to $6 \mathrm{GHz}$ and up to $190 \mathrm{GHz}$ (extrapolating the SSM/I emissivities). These emissivities are essential for atmospheric profile retrievals over land: results for water-vapour retrieval show that surface-contaminated channels can be utilized and that the retrieval is improved, in particular for the lower troposphere. Furthermore, TELSEM emissivity first guesses can be improved in emissivity-retrieval schemes. Copyright (C) 2011 Royal Meteorological Society and British Crown Copyright, the Met Office

Key Words: remote sensing; assimilation; radiative transfer; water vapour

Received 9 August 2010; Revised 20 November 2010; Accepted 6 February 2011; Published online in Wiley Online Library 16 March 2011

Citation: Aires F, Prigent C, Bernardo F, Jiménez C, Saunders R, Brunel P. 2011. A Tool to Estimate Land-Surface Emissivities at Microwave frequencies (TELSEM) for use in numerical weather prediction. Q. J. R. Meteorol. Soc. 137: 690-699. DOI:10.1002/qj.803

\section{Introduction}

Surface-sensitive microwave observations from satellite instruments contain key information about lowertroposphere temperature and water vapour, cloud liquid water and precipitating water. Accurate estimates of microwave land-surface emissivities are essential to extract such information in any inversion scheme such as statistical or $1 \mathrm{D}-$ Var retrievals or within complex $4 \mathrm{D}$ data assimilation system used in numerical weather prediction (NWP) centres. However, surface-sensitive microwave observations have been mainly used over the ocean. Over land, the surface 
emissivity is complex to obtain from modelling, being spatially very variable and dependent upon a large number of parameters (e.g. soil moisture, vegetation, snow cover). They are also difficult to estimate from satellite observations: they are usually higher (close to unity, compared with low ocean emissivities), limiting the contrast with the atmospheric contribution. However, recent attempts have been made over continental regions to use $\mathrm{e}^{\dagger}$ surface emissivities estimated from satellite observations (Aires et al., 2001; Karbou et al., 2005a).

In order to retrieve the surface emissivities and/or to perform satellite retrievals over land, various techniques can be used: direct estimation from satellite observations if only emissivity retrieval is necessary (Prigent et al., 1997), statistical retrievals (Aires et al., 2001) or 1D-Var assimilation in NWP in order to perform multiple retrievals simultaneously (i.e. surface plus atmospheric retrievals). Most of them require a good (i.e. close enough to the true state) emissivity first guess (FG) that is refined during the inversion process (Aires et al., 2001). In order to avoid 'incest' problems, this FG should be independent of the satellite observations used in the retrieval. A pre-calculated monthly-mean emissivity climatology can be used, but the FG needs to be as close as possible to the real emissivities, in particular taking into account not only the location and season but also the angle, frequency and polarization dependencies.

Land-surface emissivity models have been developed for various surface conditions over the globe (Weng et al., 2001; Pellerin et al., 2003), but they require a large number of input parameters that are not easily available such as soil composition, soil moisture, vegetation and snow characteristics. In parallel, global land surface emissivity datasets have been produced directly from satellite observations using Special Sensor Microwave/Imager (SSM/I) measurements (Prigent et al., 1997; 2006) or, using the same methodology, from the Advanced Microwave Sounding Units (AMSU) (Prigent et al., 2005a; Karbou et al., 2005b). These estimations are made under clear-sky conditions. The principle is simple: the signal that is measured by the satellite instrument is the sum of two terms, one related to the surface and one to the atmosphere. If the atmospheric term can be estimated, the term associated with the surface can then be easily inferred. The International Satellite Cloud Climatology Project (ISCCP) (Rossow and Schiffer, 1999) provides cloud-flag information and ancillary data are used to estimate the atmospheric contribution. This approach can be difficult to implement directly in an atmospheric retrieval scheme for the following reasons.

- It requires a cloud-clearing procedure (NWP systems suffer from the quality of their cloud flag).

- An estimation of the atmospheric composition is necessary: this is easy to obtain in NWP centres (this can be the short-range forecast), but can be more complex for stand-alone retrieval schemes.

- It can be computationally demanding, since it requires the use of a radiative transfer code.

Furthermore, the emissivity estimates might not be robust for all types of configuration. For instance,

${ }^{\dagger}$ In section 3.2 we show how to use these emissivities in a retrieval scheme. for a given period of time, AMSU only provides a limited number of overpasses of the same location with the same incidence angle, and does not give access to the vertical and horizontal polarization information separately.

In a previous work (Prigent et al., 2008), a parametrization of the land-surface emissivities between 19 and $100 \mathrm{GHz}$ under all observing conditions has been derived. It is based on an analysis of the frequency, angular, and polarization dependences of the emissivities calculated from SSM/I, Tropical Rainfall Measuring Mission (TRMM) Microwave Instrument (TMI) and AMSU. We used this parametrization to develop the Tool to Estimate LandSurface Emissivities at Microwave frequencies (TELSEM). This emissivity interpolator allows us to obtain an emissivity FG for each location over the globe and for any month of the year. Its range of frequencies is $19-100 \mathrm{GHz}$ but we will show that it can be used in extrapolation mode for lower or higher frequencies. It can provide an emissivity FG for any incidence angle and polarization configuration. TELSEM has been implemented in the RTTOV model (Saunders et al., 1999), to provide microwave radiance users with a robust estimation of the microwave emissivity over land. This new facility should be useful for radiative transfer studies, retrieval schemes or assimilation in NWP models. TELSEM is not intended to estimate emissivities based on the actual satellite observations; it provides a good FG independent of the satellite observations. TELSEM provides realistic emissivity uncertainties, estimated to be lower than 0.02 in snow-free regions, and also includes error-covariance matrices that include the reference climatology uncertainties and the emissivity interpolator errors.

Note that this microwave emissivity tool is generic and flexible: it can be interfaced with other radiative codes such as the Community Radiative Transfer Model (CRTM) developed by the Joint Center for Satellite Data Assimilation (JCSDA) (Weng et al., 2005).

In section 2 , the emissivity interpolation method is summarized and the reference surface-emissivity climatology from SSM/I observations is presented, along with the emissivity dataset from multiple instruments used to calibrate the interpolator. The interpolation principle and its implementation are commented on, and the uncertainty characterization is described. TELSEM is mainly designed to provide a FG to be improved in a retrieval scheme but the TELSEM emissivities can also directly be useful as a valuable emissivity estimation. Three applications of these estimates are presented in section 3. First, the impact of TELSEM on radiativetransfer simulations for AMSU-A and B instruments on board the National Oceanic and Atmospheric Administration (NOAA)-17 platform is measured. Second, results of atmospheric water-vapour retrievals over land are analyzed using Advanced Microwave Scanning Radiometer (AMSR)-E and Humidity Sounder for Brazil (HSB) observations, called hereafter 'AQUA observations'. Third, the TELSEM emissivity estimate is then improved in a statistical retrieval scheme. Conclusions and perspectives are drawn in section 4. 
2. The land-surface emissivity estimates, its associated errors, and its implementation in the radiative transfer code

\subsection{The reference climatology}

A monthly-mean emissivity database has been produced and analyzed for the 1993-2004 period from SSM/I measurements (Prigent et al., 2006) by removing the contribution of atmosphere, clouds, rain and surface temperature, using ancillary data and radiative-transfer calculations. The emissivities are estimated from SSM/I observations, i.e. at $19.35,22.235,37.0$, and $85.5 \mathrm{GHz}$, for both vertical and horizontal polarizations (with the exception of $22 \mathrm{GHz}$, which is vertical polarization only), with $53^{\circ}$ incidence angle. They are available with a spatial resolution of $0.25^{\circ} \times 0.25^{\circ}$ at the equator (equal-area grid). These emissivities have been thoroughly analyzed. They provide key information on the surface characteristics and have been used in numerous applications (Prigent et al., 2001; 2007; Aires et al., 2005; Jimenez et al., 2009). A reference SSM/I-derived land-surface-emissivity climatology is derived from this dataset.

\subsection{TELSEM calibration dataset}

In order to derive general estimates of the emissivities, landsurface emissivities calculated at the European Centre for Medium-range Weather Forecasts (ECMWF) under a large range of frequencies, incidence angles and polarizations have been analyzed for SSM/I, TMI and AMSU-A observations for two months (July 2002 and January 2003) over the globe. TMI frequencies are similar to the SSM/I ones, with the addition of a lower frequency channel $(10.65 \mathrm{GHz})$, for both polarizations. In addition to the $\mathrm{O}_{2}$ sounding channels around $55 \mathrm{GHz}$, AMSU-A has window channels at 23.8, 31.4, 50.2 and $89 \mathrm{GHz}$. It is a cross-track scanning instrument, with 30 scan positions up to $58.5^{\circ}$. The polarization rotates with the scan angle due to the rotating-reflector/fixed-feed type of antenna design and is a known mix of vertical and horizontal polarizations. The emissivity calculation method follows closely the scheme previously developed for SSM/I (Prigent et al., 2006). In the calculations performed at ECMWF, the selection of the clear pixels is based on the ECMWF forecast model and the atmospheric contribution is also calculated from the ECMWF forecast-model variables using RTTOV.

In order to facilitate the analysis of the frequency and angular dependences of the SSM/I, TMI and AMSU emissivities, the dataset is sorted per surface type, using a classification of the SSM/I emissivity itself based on the reference SSM/I emissivity dataset. This ensures that each class represents a different behaviour in terms of microwave emissivities and that the set of classes describes the full variability of these emissivities. The frequency and angular dependence of the satellite-derived emissivities are then analyzed for each surface type. Five surface types are identified for snow-free regions, from dense forest to deserts, and four snow types are isolated. The tenth class indicates pixels that contain standing water.

\subsection{The emissivity parametrization}

Analysis of this calibration dataset showed that the frequency, angular and polarization dependences are related to surface types but can be parametrized rather simply, with the SSM/I-derived monthly-mean emissivity climatology as a basis for the parametrization (Prigent et al., 2008). For each surface type, the angular and frequency dependences are smooth enough to describe using simple polynomial functions, anchored to the SSM/I emissivity climatology.

The interpolator is composed of the following steps (see Figure 1).

- For the location (latitude and longitude) and month selected by the user, the algorithm searches for the corresponding SSM/I emissivity in the reference climatology. It gives $\operatorname{Em}_{\mathrm{SSMI}} V\left(53^{\circ}\right)$ and $\operatorname{Em}_{\mathrm{SSMI}} H\left(53^{\circ}\right)$, i.e., the vertical and horizontal polarization emissivities at $53^{\circ}$ incidence angle, for the SSM/I frequencies at $19.35,37.0$ and $85.5 \mathrm{GHz}$.

- Then for each SSM/I frequency (19.35, 37.0, $85.5 \mathrm{GHz}$ ), the algorithm calculates the corresponding emissivity at nadir $\operatorname{EmV}\left(0^{\circ}\right)$ (which equals $\operatorname{EmH}\left(0^{\circ}\right)$ ) from a multilinear regression of $\operatorname{Em}_{\mathrm{SSMI}} V\left(53^{\circ}\right)$ and $\mathrm{Em}_{\mathrm{SSMI}} H\left(53^{\circ}\right)$. The coefficients of this multilinear regression have been pre-calculated for each class, separately.

- The next step consists of applying a pre-computed polynomial function that describes the angular dependence for each polarization and each SSM/I frequency to deduce the emissivities $\operatorname{Em} V\left(\theta^{\circ}\right)$ and $\operatorname{EmH}\left(\theta^{\circ}\right)$ at the incidence angle $\theta$ selected by the user.

- Finally, a linear interpolation in frequency is applied to derive $\operatorname{EmV}\left(\theta^{\circ}\right)$ and $\operatorname{EmH}\left(\theta^{\circ}\right)$ at the user's selected frequency from the three SSM/I frequency emissivity functions.

It should be mentioned that a climatology has been used to define, in the reference-emissivity climatology, the location of snow-covered pixels. It is expected that the use of this snow climatology will bring problems during snowmelt/freezing because, for a particular date, the reality of the situation can be different from the climatology.

The validity of the regression coefficients is optimal for the $19-85 \mathrm{GHz}$ frequency range of SSM/I. However, tests

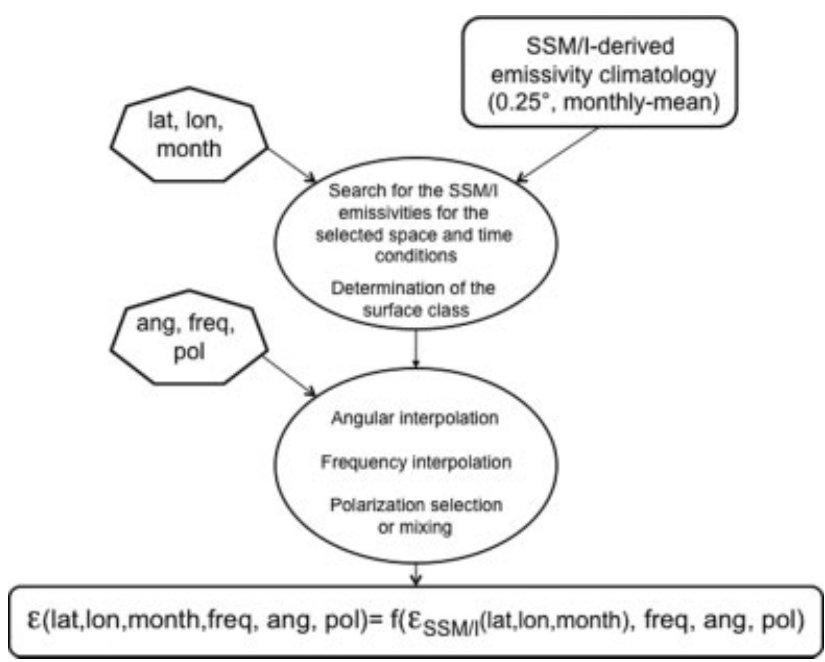

Figure 1. The different steps in TELSEM. 


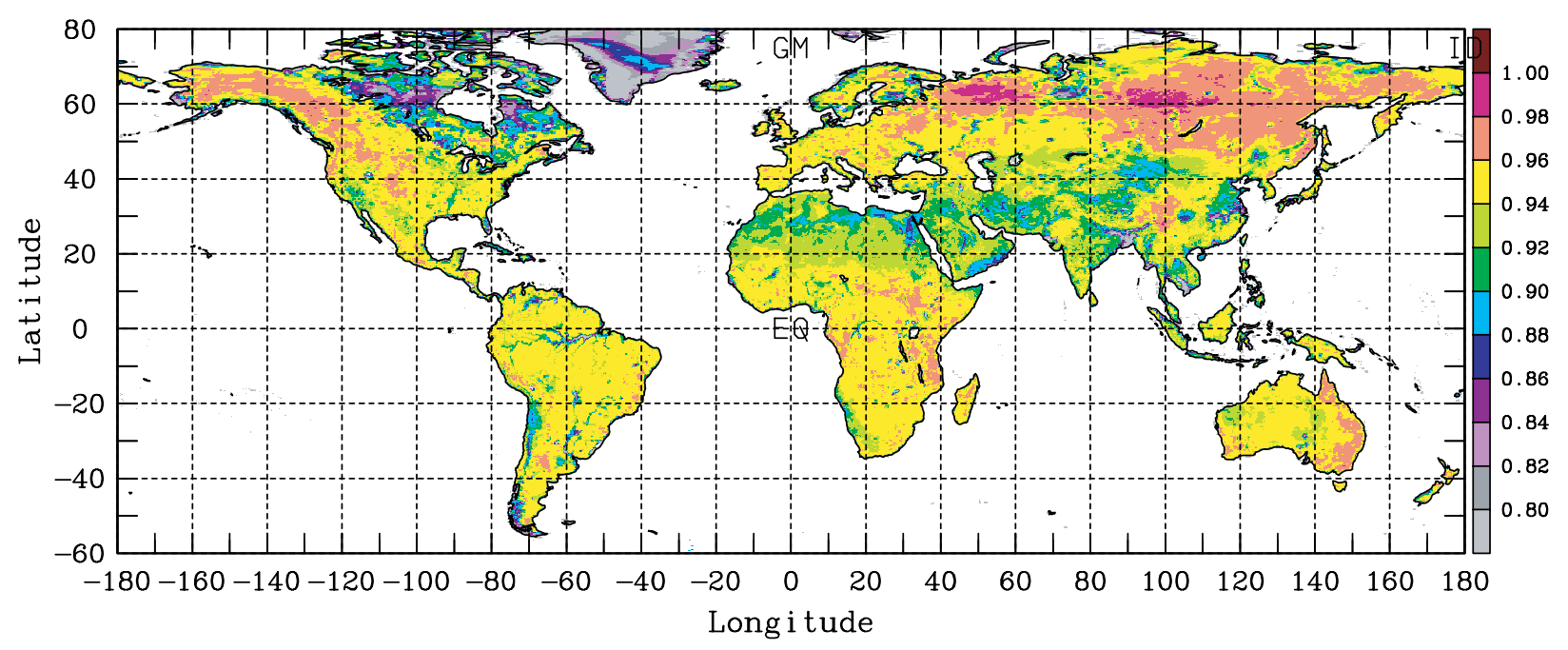

Figure 2. Example of emissivity calculation with TELSEM for September at $31.4 \mathrm{GHz}$ (AMSU-A channel), for $15^{\circ}$ incidence angle and vertical polarization.

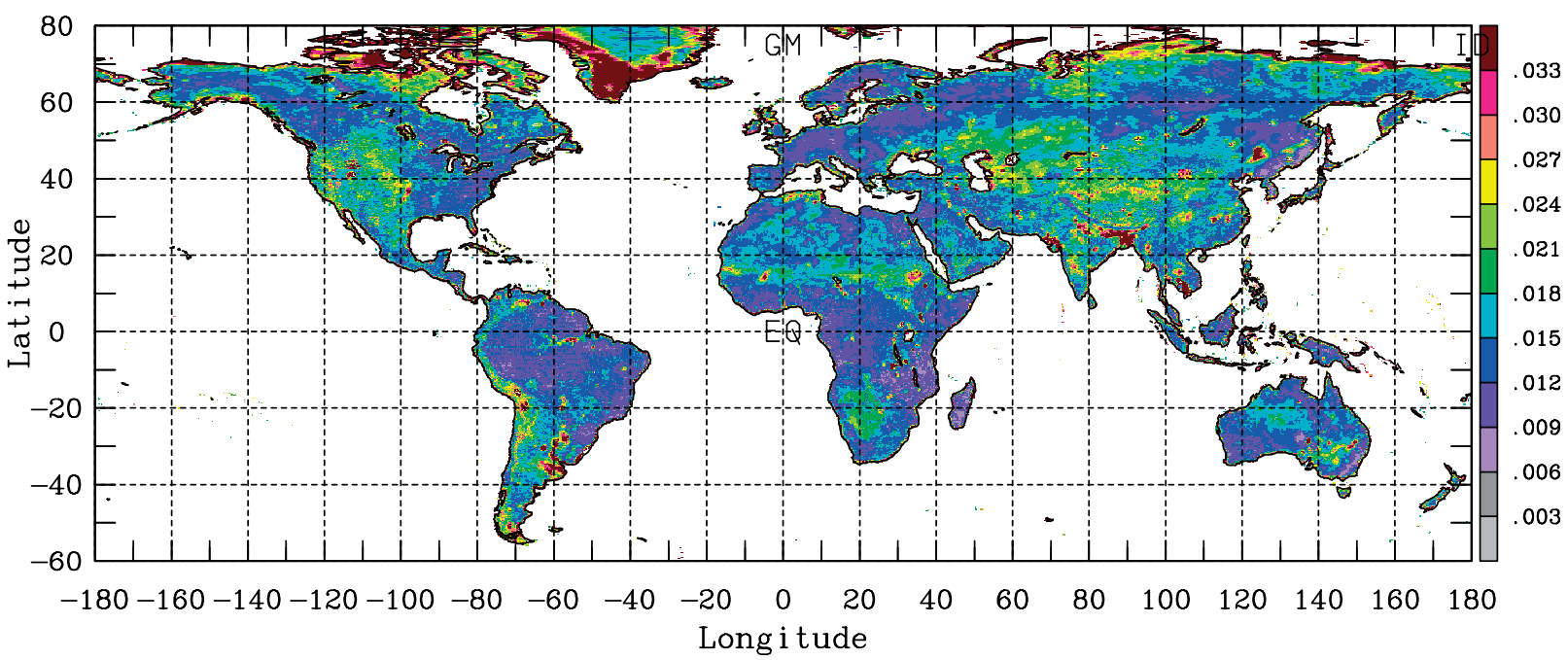

Figure 3. The emissivity uncertainty estimates for September, interpolated at $31.4 \mathrm{GHz}$ (AMSU-A channel), for the vertical polarization at $15^{\circ}$ incidence angle.

show that TELSEM can be useful in frequency-extrapolation mode. For frequencies lower than $19 \mathrm{GHz}$, the $19 \mathrm{GHz}$ emissivities are adopted. This has been evaluated down to $6 \mathrm{GHz}$ (see section 3). For frequencies higher than $85 \mathrm{GHz}$, the $85 \mathrm{GHz}$ emissivities are used. AMSU-B emissivities at $150 \mathrm{GHz}$ have been calculated directly from the satellite observations as described above. However, these calculations showed large variabilities related to water-vapour errors and cloud contamination ${ }^{\ddagger}$ and tests proved that the use of the $85 \mathrm{GHz}$ emissivity estimates was more reliable (Karbou et al., 2005b).

Figure 2 shows an example of emissivity interpolation for September at $31.4 \mathrm{GHz}$, for a $15^{\circ}$ incidence angle and vertical polarization (i.e. quite different conditions compared with the reference climatology that is used, with SSM/I channel frequencies and a constant incidence angle of $53^{\circ}$ ). The interpolation scheme preserves the spatial structure of the microwave emissivities, for instance the

¥A rather old version of the ECMWF model has been used here and improvements in the quality of the ECMWF analysis/forecast are likely to improve the results. hydrological features in South America or the geologically related information in the North African desert (Prigent et al., 2005b). More details on the parametrization and its evaluation are provided in Prigent et al. (2008).

\subsection{Estimation of the error-covariance matrices of the interpolated emissivities}

For most applications the errors associated with the emissivities have to be evaluated, as this information is essential for most retrieval scheme, especially in assimilation systems. When emissivities under several conditions (at different frequencies or polarizations for instance) are used together, the covariance matrix of these errors also needs to be estimated.

An error budget has been estimated for the reference SSM/I-derived emissivities taking into account the various sources of errors in the calculation (Prigent et al., 1997): the accuracy of the instantaneous retrieved emissivities is estimated to be within 1-2\%. At monthly mean scales, the standard deviation of the emissivity calculation for each frequency is considered as a measure of the error. Careful analysis and comparisons with other emissivity products 
Table I. The correlation matrix for uncertainties in the reference SSM/I emissivity climatology for forested regions (class 1).

\begin{tabular}{llllllll}
\hline SSM/I Channels & $19 \mathrm{~V}$ & $19 \mathrm{H}$ & $22 \mathrm{~V}$ & $37 \mathrm{~V}$ & $37 \mathrm{H}$ & $85 \mathrm{~V}$ & $85 \mathrm{H}$ \\
\hline $19 \mathrm{GHz} \mathrm{V}$ & 1.00 & 0.96 & 0.92 & 0.96 & 0.94 & 0.72 & 0.73 \\
$19 \mathrm{GHz} \mathrm{H}$ & 0.96 & 1.00 & 0.90 & 0.95 & 0.95 & 0.71 & 0.72 \\
$22 \mathrm{GHz} \mathrm{V}$ & 0.92 & 0.90 & 1.00 & 0.92 & 0.91 & 0.78 & 0.78 \\
$37 \mathrm{GHz} \mathrm{V}$ & 0.96 & 0.95 & 0.92 & 1.00 & 0.96 & 0.79 & 0.79 \\
$37 \mathrm{GHz} \mathrm{H}$ & 0.94 & 0.95 & 0.91 & 0.96 & 1.00 & 0.76 & 0.78 \\
$85 \mathrm{GHz} \mathrm{V}$ & 0.72 & 0.71 & 0.78 & 0.79 & 0.76 & 1.00 & 0.93 \\
$85 \mathrm{GHz} \mathrm{H}$ & 0.73 & 0.72 & 0.78 & 0.79 & 0.78 & 0.93 & 1.00 \\
\hline
\end{tabular}

validated this approach. The challenge is now to adjust these SSM/I emissivity errors for the new interpolated emissivities.

Let $E m_{\mathrm{SSMI}}(6)$ be the six-channel SSM/I emissivities from the reference climatology for the $19 \mathrm{~V}, 19 \mathrm{H}, 37 \mathrm{~V}, 37 \mathrm{H}$, $85 \mathrm{~V}$ and $85 \mathrm{H}$ channels. The SSM/I reference-emissivity climatology also provides the $6 \times 6$ correlation matrix, $\operatorname{Cor}_{\mathrm{SSMI}}(6,6)$, for the uncertainties for the 6 SSM/I channels together with the associated uncertainty standard-deviation vector, $S t d_{S S M I}(6)$. The covariance matrix of the SSM/I emissivity uncertainties can easily be estimated using

$$
\operatorname{Cov} v_{\mathrm{SSMI}}=\operatorname{St} d_{\mathrm{SSMI}}^{\mathrm{T}} \cdot \operatorname{Cor}_{\mathrm{SSMI}} \cdot \operatorname{Std}_{\mathrm{SSMI}} \text {, }
$$

where ${ }^{\mathrm{T}}$ denotes the transpose of the matrix. A study has been conducted using the reference climatology to measure the variability of the correlation of errors for all pixels on a particular surface type. It appears (not shown) that the matrices CorsSI are quite robust: for a particular surface type, the standard deviations of the correlations are small compared with the actual correlation. This means that, for each of the ten surface types, a unique error-correlation matrix Cor $_{\text {SSMI }}$ can be estimated and then used. An example of such a correlation matrix is given in Table I for class 1 (i.e. highly vegetated areas). The structure of this matrix is complex for each vegetation class and it varies from one class to another. The correlations between channels are highly significant and cannot be neglected. In particular, it is important to use this correlation structure in a variational assimilation experiment and in all inversion schemes in general. If the covariance-error matrix is assumed diagonal (i.e. only the standard deviations of errors are accounted for), the uncertainties are underestimated. The fact that a single correlation matrix is used for all situations for a given surface type is a simplification that allows for a faster use of the interpolator, without any significant loss of accuracy.

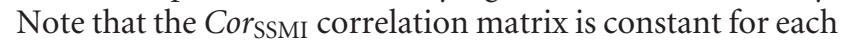
surface type but the $S t d_{S M I}$ standard-deviation matrix in the $\mathrm{SSM} / \mathrm{I}$ emissivity climatology is provided by the interpolator, so that each spatial location over land will have a different $\operatorname{Cov}_{\text {SSMI }}$ covariance matrix (Eq. (1)).

The goal of the emissivity interpolator is to estimate new emissivities $\operatorname{Em}_{\mathrm{NEW}}(f)$, where $f$ is the number of new frequencies to be calculated by the interpolator (at different scanning angles and polarizations). The first half of $E m_{\mathrm{NEW}}$ is for the vertical polarizations and the second half for the horizontal ones (this is the way it was implemented in the TELSEM code). The emissivity parametrization described in section 2.3 allows for the estimation of $\operatorname{Em}_{\mathrm{NEW}}(f)$ using a $(f \times 6)$ matrix, $A$, such that

$$
\left(E m_{V} ; E m_{H}\right)=A \cdot E m_{\mathrm{SSMI}} .
$$

The difficulty is then to make a realistic assessment of the errors of the interpolated emissivities. Simple algebra shows that the covariance matrix of the new emissivity uncertainties can be estimated by

$$
\begin{aligned}
\operatorname{Cov}_{\mathrm{NEW}} & =A^{\mathrm{T}} \cdot \operatorname{Cov}_{\mathrm{SSMI}} \cdot A \\
& =A^{\mathrm{T}} \cdot \operatorname{Std}_{\mathrm{SSMI}}^{\mathrm{T}} \cdot \operatorname{Cor}_{\mathrm{SSMI}} \cdot \operatorname{Std}_{\mathrm{SSMI}} \cdot A .
\end{aligned}
$$

As a consequence, TELSEM not only provides a set of emissivities at new frequencies, angles and polarizations, but also estimates the full covariance matrix for this new set of channels.

In summary, the standard-deviation matrix $S t d_{S S M I}$ and the corresponding correlation matrix CorsSMI are provided by the reference-emissivity climatology. The interpolator calculates the new covariance matrix Cov $v_{\mathrm{NEW}}$ for each location over land, and for each month, for the frequencies specified by the user. Figure 3 provides the uncertainty estimates interpolated at $31.4 \mathrm{GHz}$ for the vertical polarization at $15^{\circ}$ incidence angle for September (associated with the emissivity estimates of Figure 2). As expected, large uncertainties are related to temporally variable features such as wetlands (e.g. over Bangladesh) or snow- or ice-covered regions (e.g. over Greenland).

\subsection{Implementation of the emissivity module in the RTTOV code}

The RTTOV model has been developed for very rapid calculations of radiances in the infrared and microwave, primarily for use in variational assimilation of satellite observations within NWP centres (Saunders et al., 1999). It was jointly developed by the Met Office (UK), MétéoFrance and ECMWF in the framework of the EUMETSATfunded NWP Satellite Application Facility and also other EUMETSAT sponsored activities. The original code was described by Eyre and Woolf (1988). Matricardi et al. (2004) presents more recent developments. It is a compromise between calculation accuracy and speed. The absorption models are parametrized to produce regressions as a function of a selection of model predictors such as temperature and humidity, based on training datasets of accurate line-by-line absorption models and representative atmospheric-profile aspects. RTTOV-9 was released in 2008 and computes seasurface emissivity as a function of surface wind speed, using the FASTEM-3 code developed by Deblonde and English (2001). ${ }^{\S}$ However, it does not provide accurate estimates

${ }_{\text {See http://www.metoffice.com/research/interproj/nwpsaf/rtm/rttov8 }}$
_svr.pdf. 
of the land-surface emissivity: a fixed microwave surfaceemissivity value is suggested for each channel (English and Hewison, 1998), regardless of the observing conditions (the impact of such a simplification will be measured in section 3 and in Figure 4).

The TELSEM parametrization has been added as a new tool to the RTTOV simulator. The only information to be provided by the user is the geographical location (latitude and longitude) and the month. The nominal spatial resolution of the emissivity estimates is $0.25^{\circ} \times 0.25^{\circ}$ but, if desired, the user can specify another spatial resolution (always degraded compared with the initial one): the code can use the closest climatology-derived emissivity or it will perform spatial averaging. The calculation can be performed individually for single frequency channels but also for multiple channels, in which case error-covariance matrices are provided. TELSEM simulations are very fast. However, it is recommended that TELSEM users interested in a particular instrument generate once and for all their own reference-emissivity climatology at the relevant horizontal resolution. This new reference climatology can then be used as a convenient FG or a simple emissivity estimate.

\section{Impact of TELSEM on forward and inverse radiative transfer}

TELSEM emissivities are not regular emissivity estimates, rather they are a FG climatology that can be used for many different instruments and various observing conditions. In this section, we measure the impact of this tool on radiativetransfer simulations and on atmospheric retrievals over land.

\subsection{Comparison with AMSU-A and $-B$ observations on board NOOA-17}

In order to evaluate TELSEM emissivities, RTTOV radiative-transfer calculations have been performed with and without the new tool and compared with satellite observations. Comparisons are also performed using emissivities simulated at ECMWF with the radiative-transfer model from Weng et al. (2001). The inputs for these model-based emissivity calculations are provided by the forecast model (e.g. soil temperature and humidity, vegetation fraction or snow characteristics). This model uses different solutions depending on the surface type.

For this experiment, observations from NOAA-17 are collected for July 2002 and January 2003, in order to sample the seasonal cycle. The observations from the AMSU$A$ and -B cross-track sounders are first collocated. The atmospheric profiles and relevant surface parameters are extracted from the ECMWF analysis in order to have all the required information needed to perform radiativetransfer simulations. High-elevation locations (>1000 m), precipitating scenes and high-latitude points (lat $>60^{\circ}$ ) are suppressed from the statistics. All incidence angles are included in these statistics.

Figure 4 compares the simulated and observed brightness temperatures (TBs): the two upper graphs are for bias statistics, while the bottom graphs are for the root-meansquare (RMS) differences. Left (resp. right) graphs are for clear (resp. cloudy) situations. Simulations are performed with TELSEM emissivities, with a constant emissivity corresponding to the default RTTOV model and with the Weng et al. (2001) model. All these statistics are for continental surfaces but, for comparison purposes, the simulations have been performed over the ocean as well, with emissivities calculated with the FASTEM model (Deblonde and English, 2001).

The results are clearly better with the new TELSEM landsurface emissivities, and are similarly good for clear and cloudy scenes in term of both bias and RMS error statistics.

As expected, the stand-alone RTTOV constant emissivity introduces high bias errors on surface-sensitive channels. These large errors dominate the corresponding RMS errors. When the new TELSEM emissivities are used, these biases are reduced very significantly, close to zero. This reduction of the bias when using TELSEM has an important impact on the RMS statistics, with errors reduced by a factor of 3-4 for window channels. With TELSEM, RMS errors are always lower than with the stand-alone RTTOV emissivity or with the model-based calculations (model-based emissivities are highly dependent on the quality of the inputs of the model such as soil mositure or vegetation, which is a difficulty with this approach). As expected, there is no impact of the emissivity changes for opaque channels around $183 \mathrm{GHz}$ or temperature-sounding channels. No bias correction procedure is used for these comparison statistics, explaining part of the remaining differences.

Furthermore, the agreement between simulations and observations obtained with the new TELSEM surface emissivities is, for most channels, better than the one obtained over the ocean with FASTEM. Note that the fact that the RMS errors over ocean are larger than over land is likely not exclusively related to emissivity problems, but to the higher sensitivity to water vapour and clouds over the ocean. At $157 \mathrm{GHz}$, the $85 \mathrm{GHz}$ emissivity is adopted in TELSEM: the effect is not large compared with the stand-alone RTTOV or the Weng model but is still positive, showing that this rather crude extrapolation is still beneficial. At this frequency and higher, the RMS error between the simulations and the observations is driven by the atmospheric components, with very similar behaviour over land and ocean for both clear and cloudy situations.

Land and ocean statistics being similar, even for surfacesensitive channels, means that the introduction of realistic microwave emissivities increases the accuracy of the forward radiative-transfer simulations. As a consequence, the accuracy of the retrieval of atmospheric parameters over land should be improved."

\subsection{Impact of the land-surface emissivity in the inversion of atmospheric profiles}

A French-Indian satellite mission, Megha-Tropiques, will be launched in 2011 (Desbois et al., 2007). Its objective is to study the water cycle in the Tropics, with a high temporal sampling. Megha-Tropiques will carry two microwave instruments: a conical imager, Madras, with frequencies at $18.7,23.8,36.5,89$ and $157 \mathrm{GHz}$ for both linear polarizations,

\footnotetext{
The use of real observations in a remote-sensing code generally requires some bias tuning of the data so that the RTM simulations are close enough to the real observations (Aires et al., 2010).

"Of course, given the brightness-temperature surface/atmosphere contrasts, retrievals are expected to be easier over ocean.
} 
(a) $\quad \mathrm{RT}$ (Analysis + Emissivity) - Obs, clear situation

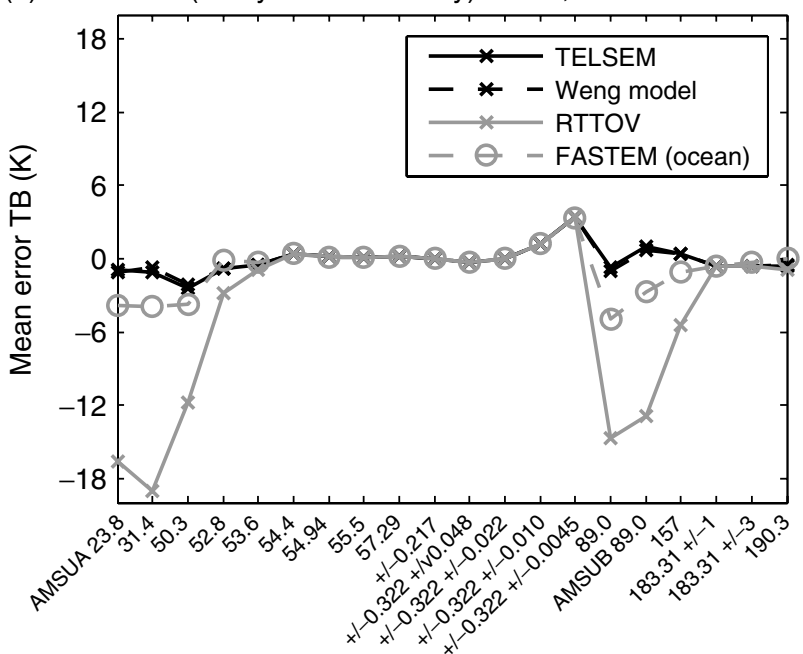

(c) $\quad$ RT(Analysis + Emissivity) - Obs, clear situation

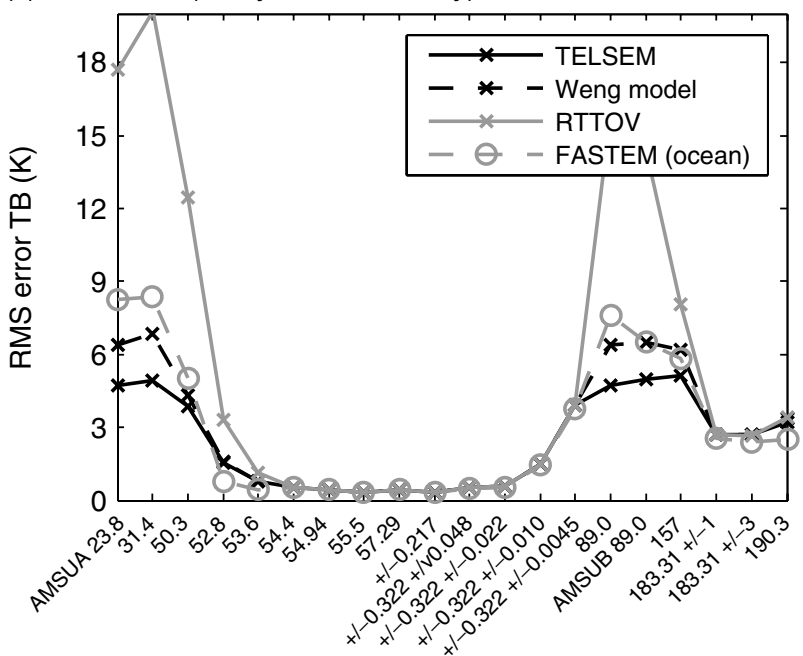

(b)

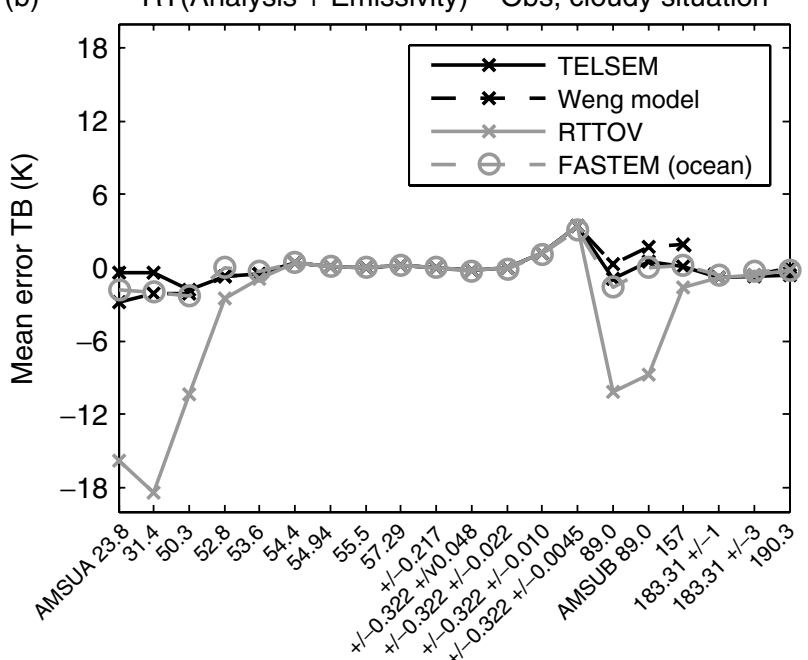

(d)

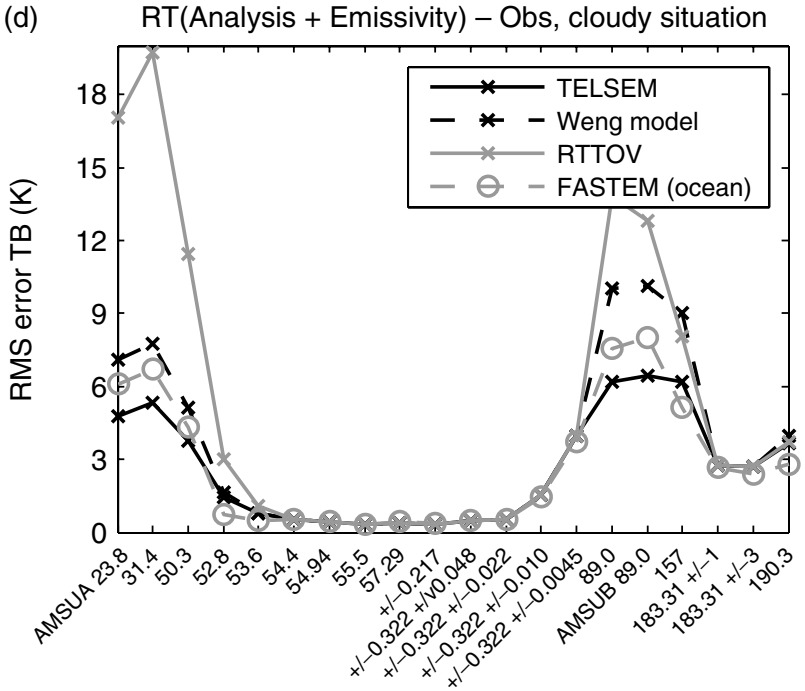

Figure 4. RMS errors between simulated and observed TBs for AMSU-A and AMSU-B on board NOAA-17, for two months (July 2002 and January 2003). High latitudes $\left( \pm 60^{\circ}\right.$ in latitude) and precipitating scenes have been excluded from the statistics. (a) Bias statistics for cloud-free situations, (b) bias for cloudy situations, (c) RMS statistics for cloud-free situations, (d) RMS for cloudy situations. The continuous black line denotes the simulations with the TELSEM emissivities, the continuous grey line the original RTTOV simulations using a fixed emissivity from a stand-alone RTTOV and the dashed black line emissivities from the Weng model. For comparison purposes, similar statistics are performed over the ocean using the FASTEM emissivity model, shown as the dashed/circle grey line.

and a cross-track humidity sounder, Saphir, with six channels around the $183 \mathrm{GHz}$ water-vapour line. A neural network inversion has been developed to derive, among other variables, the water-vapour atmospheric profiles from the combination of the Madras and Saphir observations. The statistical method is trained on a simulated database using a global collection of ECMWF analysis coupled to the RTTOV radiative-transfer model. The operational inversion algorithm uses the new RTTOV tool to estimate the emissivities over land.

In order to evaluate the operational chain, tests have been conducted on existing satellite data at similar frequencies, using AMSR-E and HSB observations from AQUA, over the Tropics $\left( \pm 30^{\circ}\right)$ for two months (July 2002 and January 2003). Tests have been performed both in the forward and inverse modes. In the forward mode, similarly to Figure 4, the RMS errors between simulated and observed TBs are significantly better with TELSEM than with the fixed RTTOV emissivities, even at the lower AMSRE frequency channels 6.925 and $10.65 \mathrm{GHz}$, where the
TELSEM emissivities at $19 \mathrm{GHz}$ are adopted: for horizontal polarization channels, the RMS errors decrease from close to $30 \mathrm{~K}$ with RTTOV emissivities to around $10 \mathrm{~K}$ (the impact for vertical polarization channels is limited, with RMS errors around $6 \mathrm{~K})$.

Figure 5 shows the RMS errors (or departures) for the retrieval of the relative humidity, calculated from the difference between the satellite retrieval and the analysis from ECMWF, assuming that the ECMWF analysis is the truth. For both clear and cloudy atmospheres, the results show that the retrieval accuracies for the lower layers below $750 \mathrm{hPa}$ are of the same order (around 10-20\% in RMS) over land and ocean. This is very encouraging. So far, observations from surface-sensitive channels over land have been disregarded. These results suggest that the use of realistic emissivity estimates can considerably increase the number of satellite observations to be assimilated over land, and provides estimates of atmospheric profiles in the lower layers over land with accuracies that are comparable to the accuracies over the ocean. 


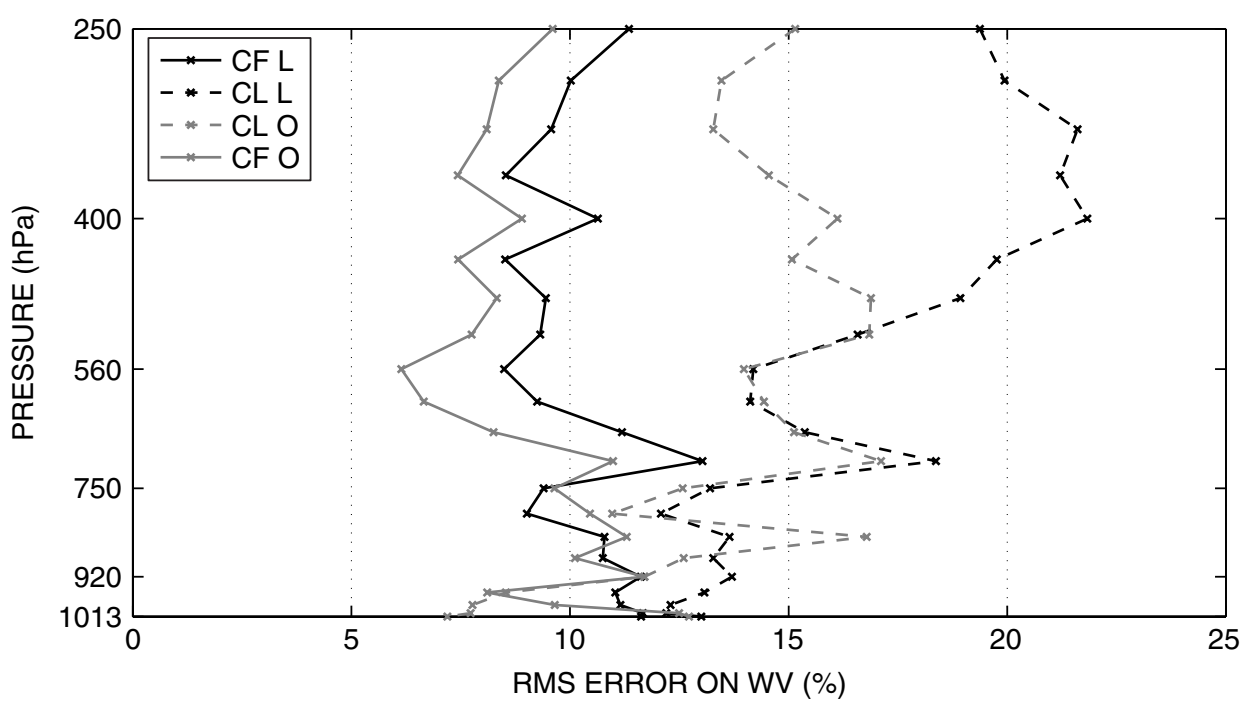

Figure 5. RMS relative error for the AMSR-E/HSB retrieval of relative humidity (in \%). The statistics are given over the tropical regions $\left( \pm 30^{\circ}\right)$ for July 2002 and January 2003. Grey lines are for ocean surfaces $(\mathrm{O})$ and black lines for land $(\mathrm{L})$. Continuous lines are for cloud-free $(\mathrm{CF})$ scenes and dashed lines are for cloudy $(\mathrm{CL})$ situations.

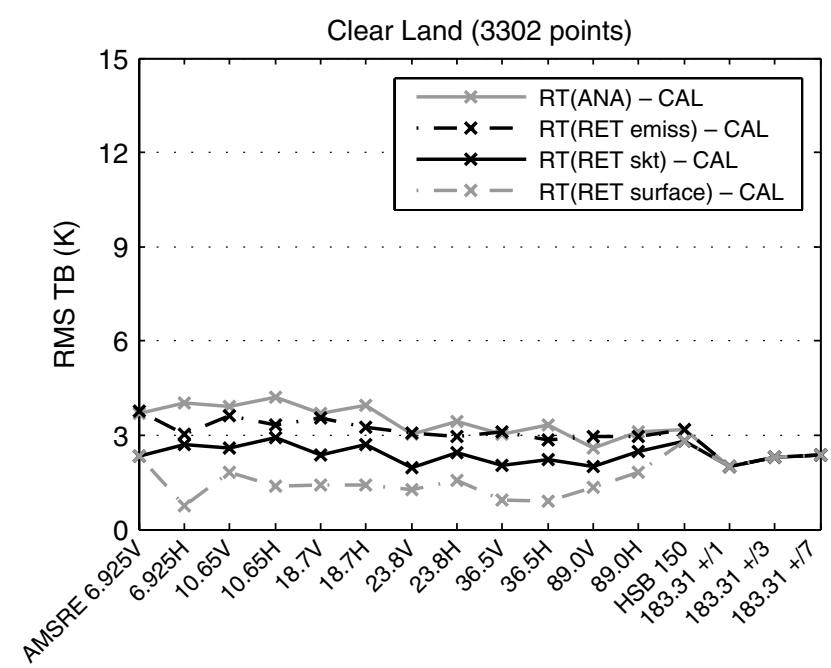

Figure 6. RMS errors between simulated and observed TBs for AMSR-E and HSB instruments on board AQUA, for two months (July 2002 and January 2003). High latitudes $\left( \pm 60^{\circ}\right.$ in latitude), cloudy and precipitating scenes have been excluded from the statistics. RTTOV simulations use the following surface conditions: continuous grey line, FG information (TELSEM emissivities and TS from analysis); dashed black line, NN inverted emissivities only; continuous black line, TELSEM emissivities but NN Ts retrieval; dashed grey line, both surface emissivities and skin temperature from the NN retrieval.

\subsection{Retrieval of the land-surface emissivity using TELSEM first guesses}

In this section, the TELSEM emissivities are used as FG in a retrieval scheme that simultaneously inverts the surface skin temperature and emissivities. Similarly to section 3.2, the satellite observations come from the AMSR-E and HSB instruments on board the AQUA platform. The retrieval approach is similar to that used in Aires et al. (2001): a neural network (NN) uses as inputs a mix of information composed of the actual satellite observations plus a FG of both emissivities and surface skin temperature. The outputs are new estimates of surface temperature and emissivities. The training of the $\mathrm{NN}$ is carried out on an independent training dataset composed of radiative transfer
(RT) simulations performed with the RTTOV model. The emissivities are the TELSEM outputs and the emissivity FGs are the same emissivities perturbed by a FG error noise equal to the TELSEM errors.

After the training stage, the NN inversion scheme can be tested on real AQUA measurements. The FG information is provided by the TELSEM estimates and the ECMWF analysis gives the surface skin temperature. The NN estimates new values for both variables. In order to test their quality, RT simulations are performed using, similarly to section 3.1, the ECMWF analysis plus surface information. Figure 6 presents the RMS differences between the RT simulations and the real observations (calibrated) when the FG or retrieved surface information are used. Four configuration are tested: (1) surface comes from the FG, (2) only emissivities come from the $\mathrm{NN}$ retrieval, (3) only the skin temperature comes from the NN retrieval and (4) both emissivities and surface skin temperature come from the NN retrieval. These statistics allow us to measure the impact of improving emissivity and temperature on the retrieval scheme. It should be noted here that since the retrieval uses a NN method, it uses a general inversion model not specific to each situation to be inverted. By contrast, a 1D-Var retrieval scheme should be even more efficient in bringing together RT simulations and real satellite observations because the inversion process, in this case, is dedicated to each new observation.

The results are very encouraging. Both retrieved skin temperature and emissivities have a significant impact on bringing RT simulations and calibrated observations closer. This shows that even if TELSEM estimates are good, they can be improved by a retrieval scheme by more than $1 \mathrm{~K}$ for some horizontally polarized channels. It is well known that the skin temperature from operational analysis is not accurate enough, and the impact of using a retrieved surface temperature, Ts, instead of the analysis is even greater than for the emissivities: almost $1.5 \mathrm{~K}$ for both horizontally and vertically polarized channels. Of course, no impact was found for the water-vapour sounding channels at $183 \mathrm{GHz}$. It is also very interesting to note that when both retrieved Ts and emissivities are used, the impact is even better and larger than just the sum of the contribution 
of both. This means that there is synergy in retrieving, together, Ts and emissivities (Aires et al., 2001, 2011; Aires, 2011). This experiment shows clearly that the TELSEM emissivities are a good FG that can be improved by a retrieval scheme, and that this retrieval benefits from the simultaneous retrieval of both surface skin temperature and emissivities.

\section{Conclusion}

A Tool to Estimate Land-Surface Emissivities at Microwave frequencies (TELSEM) has been developed within the RTTOV radiative-transfer model, for a simple and convenient use by a large community. This new facility allows us easily to build surface microwave-emissivity climatologies that can be used as a realistic FG in emissivityestimation schemes and/or atmospheric retrieval algorithms over land, including variational assimilation.

TELSEM is anchored to a reference-emissivity climatology calculated from SSM/I observations. It is able to interpolate in frequencies and viewing angles for both linear polarizations. It is originally designed for frequencies between 19 and $85 \mathrm{GHz}$, but tests proved that it is beneficial down to $6 \mathrm{GHz}$ and up to $190 \mathrm{GHz}$. TELSEM also provides the full covariance matrix of the uncertainties in the interpolated emissivities, key information for most retrieval algorithms, especially for assimilation in NWP schemes.

The potential benefits of TELSEM for the inversion of surface-sensitive microwave sounding channels are illustrated by three examples. First, the emissivity interpolator has been used within the RTTOV model to simulate NOAA17 AMSU-A and -B instruments and compare the results with the corresponding real observations. Adding the landsurface emissivity information from TELSEM has a strong positive impact, with a decrease of the RMS statistics of more than $10 \mathrm{~K}$ for some channels, averaged over two months on a continental scale. Using these realistic land-surface emissivity FG estimates, the agreement between simulations and observations is similar over land and ocean, making it possible to attempt assimilation of surface-sensitive observations over the continents. A water-vapour atmospheric retrieval experiment has been conducted, from combined AMSR-E and HSB data, using an adaptation of the operational chain developed for the future Megha-Tropiques mission. The ability to reproduce the observed TBs over land directly benefits the retrieval of the lower atmospheric layer, with retrieval accuracy comparable over land and ocean. Furthermore, it has been shown that the TELSEM emissivity FGs can be significantly improved when they are updated by a simple statistical retrieval scheme. TELSEM in RTTOV will be soon tested in an assimilation scheme in a NWP centre.

This study was supported by the NWP-Satellite Application Facility. A similar effort is being conducted toward the development of an infrared land-surface emissivity calculator, based on previous work by Seemann et al. (2008). Using these two emissivity tools with RTTOV will allow microwave and infrared measurements to be assimilated in retrieval schemes over land benefiting from their synergy (Aires, 2011; Aires et al., 2011).

\section{Acknowledgement}

This work has been performed in the framework of the Visiting Scientist Programme of the EUMETSAT Satellite Application Facility on Numerical Weather Prediction (NWP SAF), http://www.nwpsaf.org

\section{References}

Aires F. 2011. Measure and exploitation of multi-sensor and multi-wavelength synergy for remote sensing: Part I - Theoretical considerations. J. Geophys. Res. 116: D02301, DOI: 10.1029/2010JD014701.

Aires F, Bernardo F, Brogniez H, Prigent C. 2010. An innovative calibration method for the inversion of satellite observations. J. Appl. Meteorol. 49(12): 2458-2473.

Aires F, Paul M, Prigent C, Rommen B, Bouvet M. 2011. Measure and exploitation of multi-sensor and multi-wavelength synergy for remote sensing: Part II - Application for the retrieval of atmospheric temperature and water vapour from METOP. J. Geophys. Res. 116: D02303, DOI: 10.1029/2010JD014702.

Aires F, Prigent C, Rossow WB, Rothstein M. 2001. A new neural network approach including first guess for retrieval of atmospheric water vapour, cloud liquid water path, surface temperature and emissivities over land from satellite microwave observations. J. Geophys. Res. 106: D14887-14907.

Aires F, Prigent C, Rossow WB. 2005. Sensitivity of microwave and infrared satellite observations to soil moisture at a global scale. II: Global statistical relationships. J. Geophys. Res. 110: D11103. DOI:10.1029/2004JD005094.

Deblonde G, English SJ. 2001. 'Evaluation of the FASTEM-2 fast microwave oceanic surface emissivity model'. In Tech. Proc. ITSC-XI Budapest, 20-26 Sept 2000; pp. 67-78. ITWG/IAMAS: Budapest.

Desbois M, Capderou M, Eymard L, Roca R, Viltard N, Violier M, Karouche N. 2007. Megha-Tropiques: un satellite hydrométéorologique franco-indien. La Météorologie 57: 19-27.

English SJ, Hewison T. 1998. A fast generic millimetre wave emissivity model. Microwave remote sensing of the atmosphere and environment. Proc. SPIE 3503: 22-30.

Eyre JR, Woolf HM. 1988. Transmittance of atmospheric gases in the microwave region: a fast model. Appl. Opt. 27: 3244-3249.

Jimenez C, Prigent C, Aires F. 2009. Toward an estimation of global land surface heat fluxes from multisatellite observations. J. Geophys. Res. 114: D06305. DOI:10.1029/2008JD011392.

Karbou F, Aires F, Prigent C, Eymard L. 2005a. Potential of AMSU-A and -B measurements for atmospheric temperature and humidity profiling over land. J. Geophys. Res. 110: D07109. DOI:10.1029/2004JD005318.

Karbou F, Prigent C, Eymard L, Pardo J. 2005b. Microwave land emissivity calculations using AMSU measurements. IEEE Trans. Geosci. Remote Sensing 43: 948-959.

Matricardi M, Chevallier F, Kelly GA, Thépaut J-N. 2004. An improved general fast radiative-transfer model for the assimilation of radiance observations. Q. J. R. Meteorol. Soc. 130: 153-173.

Pellerin T, Wigneron J-P, Calvet J-C, Waldteufel P. 2003. Global soil moisture retrieval from a synthetic L-band brightness temperature data set. J. Geophys. Res. 108: 4364. DOI:1.1029/2002JD003086.

Prigent C, Rossow WB, Matthews E. 1997. Microwave land-surface emissivities estimated from SSM/I observations. J. Geophys. Res. 102: 21867-21890.

Prigent C, Aires F, Rossow WB, Matthews E. 2001. Joint characterization of vegetation by satellite observations from visible to microwave wavelength: A sensitivity analysis. J. Geophys. Res. 106: 20665-20685.

Prigent C, Chevallier F, Karbou F, Bauer P, Kelly G. 2005a. AMSU-A land-surface emissivity estimation for numerical weather prediction assimilation schemes. J. Appl. Meteorol. 44: 416-426.

Prigent C, Munier J, Thomas B, Ruffié G. 2005b. Microwave signatures over carbonate sedimentary platforms in arid areas: Potential geological applications of passive microwave observations? Geophys. Res. Lett. 32: L23405. DOI:10.1029/2005GL024691.

Prigent C, Aires F, Rossow WB. 2006. Land surface microwave emissivities over the globe for a decade. Bull. Am. Meteorol. Soc. 87: 1573-1584. DOI:10.1175/BAMS-87-11-1573.

Prigent C, Papa F, Aires F, Rossow WB, Matthews E. 2007. Global inundation dynamics inferred from multiple satellite observations, 1993-2000. J. Geophys. Res. 112: D12107. DOI:10.1029/2006JD007847.

Prigent C, Jaumouille E, Chevallier F, Aires F. 2008. A parametrization of the microwave land-surface emissivity between 19 and $100 \mathrm{GHz}$, 
anchored to satellite-derived estimates. IEEE Trans. Geosci. Remote Sensing 46: 344-352.

Rossow WB, Schiffer RA. 1999. Advances in understanding clouds from ISCCP. Bull. Am. Meteorol. Soc. 80: 2261-2288. DOI:10.1175/1520 0477.

Saunders R, Matricardi M, Brunel P. 1999. An improved fast radiativetransfer model for assimilation of satellite radiance observations. Q. J. R. Meteorol. Soc. 125: 1407-1425.

Seemann SW, Borbas EE, Knuteson RO, Stephenson GR, Huang HL. 2008. Development of a global infrared land-surface emissivity database for application to clear sky sounding retrievals from multispectral satellite radiance measurements. J. Appl. Meteorol. Clim. 47: $108-123$.

Weng F, Yan B, Grody NC. 2001. A microwave land emissivity model. J. Geophys. Res. 106: 20115-20123.

Weng F, Han Y, van Delst P, Liu Q, Kleespies T, Yan B, Le Marshall J. 2005. JCSDA Community Radiative Transfer Model (CRTM). In International TOVS Study Conference, 14th, Beijing, China, 25-31 May 2005 (proceedings). pp. 217-222. University of Wisconsin-Madison, Space Science and Engineering Center, Cooperative Institute for Meteorological Satellite Studies (CIMSS): Madison, WI. 